\title{
Life Cycle Management
}

\section{Environmental Performance Indicators and Application of Life Cycle Thinking to Product Development and Corporate Management}

A Detailed LCM-Related Excerpt of The Fifth International Conference on Ecobalances

November 6-8, 2002, Tsukuba, Japan

\author{
David Hunkeler ${ }^{1}$, Gerald Rebitzer ${ }^{2}$ and Atsushi Inaba ${ }^{3}$ \\ ${ }^{1}$ AQUA+TECH Specialties SA, La Plaine, Geneva, Switzerland (David.Hunkeler@aquaplustech.ch) \\ ${ }^{2}$ Swiss Federal Institute of Technology, Lausanne, Switzerland (Gerald.Rebitzer@epfl.ch) \\ ${ }^{3}$ National Institute of Advanced Industrial Science and Technology, Tsukuba, Ibaraki, Japan (a-inaba@aist.go.jp)
}

\section{Introduction}

The Fifth International Conference on Ecobalances (the 5th-ICEB) held November 6-8, 2002, in Tsukuba, Japan, featured individual sessions on life cycle assessment, environmental performance indicators, life cycle thinking applied to product development and corporate management, environmental information for companies and products, industrial ecology and ecomaterials. An overview of the discussions and findings of the complete conference is given by Inaba et al. (2003).

The paper at hand covers in detail two of the six parallel sessions, which are specifically relevant for life cycle management (LCM):

- Environmental performance indicators

- Application of life cycle thinking to product development and corporate management

It terminates with a glossary of the terminology used during these and other sessions in Tsukuba. When such terms are used in the text, they are indicated with italics. Some classical definitions have also been added to the glossary for context and clarity.

\section{Environmental Performance Indicators}

This session on indicators had a variety of presentations from universities, NGOs and firms from several countries, all trying to identify which metrics are the most suitable for a given company, sector or region. Overall, the need to validate indicators via some form of systematic studies, seems to be accepted. This section in the conference, while small, has advanced significantly over the past two years. At present, many of the investigators look at life cycle validation, survey stakeholders and nonstakeholders, and examine aggregation, all areas which were proposed a few years ago in some pioneering work (Hunkeler and Biswas 2000, DeSimone and Popoff 1997).

Justus von GeIBLER, of the Wuppertal Institute, presented sustainability indicator sets based on industry surveys of various sectors. For the aluminum industry, fifty percent of the 58 internal and external stakeholders responded. The expectations between internal and external stakeholders were quite similar for environmental indicators, though different for social and economic metrics. Overall, they found 24 categories which were important for the aluminum sector, corresponding to 115 indicators, the majority of which were pre-existing.

HENRY MOLL of the University of Groningen discussed life cycle indicators for direct and indirect effects of corporate performance. Indicators included energy, land and resource-depletion, prevention of toxic and persistent substances, biodiversity as well as supply chain and waste effects. By aggregating metrics, they monitor how firms improve over a given period. However, resource, extraction and the intrinsic value of nature were not discussed.
TAK HUR of Konzuk University (Korea) discussed the measurement of green productivity. Hur's definition of productivity uses priceper-unit service divided by cost per unit service. They chose environmental impact as the denominator, rendering the green productivity indicator the same as 'Return on Environment' (Hunkeler and Biswas 2000). As a case study, polystyrene production was examined. Over $98 \%$ of environmental burdens were related to the monomer, implying that environmental improvement required improvements in mixing to reduce residual monomer levels. This also increased profitability, by $29 \%$ over ten years.

JONAZ DE MELO of the New University of Lisbon discussed EcoBlock, a method for integrated environmental performance evaluation. The goal was to develop an environmental label based on the overall environmental effect, and to have this transported through the supply chains. They selected water, material and energy use, land loss, pollution to all media and GWP as indicators and conducted a case study of construction in Portugal, revealing that the daily life has a much higher impact than the construction of the house.

KI-Hoon LEE of the Eco Frontier Co. in Korea discussed sustainable development indicators (SDIs). Given that these are macroindicators, the need for comparability with other regions is obvious. They developed 21 indicators, containing 41 parameters identifying 15 issues. Lee noted that the need to tabulate SDIs, now, is critical, since the future users will need historic information, and the act of testing the SDI permits refining them.

RYOICH YAMAMOTO described the hierarchical structure of strategies for sustainable development (SD), noting that SD requires metrics. In rationalizing the Factor- $X$ approach, Yamamoto showed that the ratio of GNP to Energy consumption should increase by a factor of 4 , within 50 years, in order to maintain current $\mathrm{CO}_{2}$ emissions. Using a linear algebra approach, and incorporating forecasted population growth and the current and desired shape of the Lorenz curve, Yamamoto predicts that Factor- 8 reductions will be required to achieve sustainability within half a century. He concluded by reporting examples, over the past 50 years, where Factor-10 to 15 improvements have been made in regards to products. For each sector, ecoefficiency indicators must be developed which will then be used to calculate Factor- $X$ values for each product, as well as for green procurement.

Mark GoedKoop of Pré Consulting in The Netherlands discussed Environmental Pressure from Private Dutch Consumption. His project was a commission from the Dutch government looking at the assessment of the overall environmental load, with the 
aim of repeating such estimations every five years. The most significant direct emissions, i.e. after the point of sale, include automobile driving to the workplace and wood and coal burning in fireplaces. Using input-output tables, the indirect effects of products, before the point of sale, were examined based on purchasing data in 105 sectors. Overall, feeding and recreation were both very high consumption domains, as was freshwater. Land use is principally exterior to The Netherlands, toxicity is principally inland and $\mathrm{CO}_{2}$ is essentially 50:50. Interestingly, the ecoindicator per unit of GNP is ten times higher for imported goods from non-OECD countries, versus domestic production, pointing to an outsourcing of pollution. A software for the presented analysis will be commercially available.

ANDREAS KICHERER of BASF presented their ecoefficiency-based sustainability method. Their aim is to compare the ecoefficiency ${ }^{1}$ of product or process alternatives, rather than to pronounce the sustainability of a given product. As one of 160 cases BASF examined the ecoefficiency of the production of indigo coloring agents for the dying of denim. Synthetic indigo, in powders and solution, must compete with bio-indigo from plants, biotech indigo and an electrochemical based dye. BASF used this data to build a new plant based on the solution process, which had identical costs, though lower environmental burdens per functional unit. Overall, BASF uses ecoefficiency in resource allocation decisions (new investments), for prioritization of research projects, to communicate with politicians and in marketing (see Saling et al. 2002).

KYYOTAKA TAHARA of AIST in Japan discussed $\mathrm{CO}_{2}$ efficiency and energy productivity, where the former is a ratio of an economic index to $\mathrm{CO}_{2}$ emissions. Tahara showed that net $\mathrm{CO}_{2}$ efficiency increased moreso than gross $\mathrm{CO}_{2}$ efficiency. If there is, as is the case in some industries, a large difference in $\mathrm{CO}_{2}$ efficiency between a sector and a specific firm, this calls for a new tax mechanism.

Li-Hsing SHIH of the National Cheng Kung University in Taiwan reported on ecoefficiency based on the analytical hierarchy process. Their cases involved expert surveys to obtain subjective weightings in the evaluation of CRT and LCD monitors.

TAEKO AOE of the Matsushita Electric Industrial Corporation discussed green product indicators. Factor- $X$ targets were calculated for various products. Television sets achieved Factor- 2 reductions in emissions in 2000 , versus 1993, while refrigerators achieved Factor 1.5 to 3.5 reductions over the 1990-2001 period. Interestingly, mobile phones achieved near Factor-4 reductions over the past eight years. They have indexes for GWP and resource use with separate Factor- $X$ targets for each fiveyear period. In terms of chemicals, evaluations lead to black lists. On an organizational level at Matsushita environmental performance is linked to staff motivation since $10 \%$ of the employee's salary is dependent on meeting Factor- $X$ targets.

YUKA OKADA of Matsushita Electric compared ecoefficiencies of various types of lamps. Overall, regional differences in the electricity mix have a strong influence on GWP and mercury emissions. Incandescent lambs had the largest GWP, with mercury, fluorescent and metal halide bulbs a similar. However, mercury emissions were highest for the round fluorescent and mercury bulbs, followed by straight fluorescent and metal halide lamps, with incandescent lamps the best in this regard, though there was a large dispersion. Matsushita prepared an aggregated index which included GWP, mercury emissions and costs, to aid consumers in purchasing decisions.

1 Ecoefficiency compares, according to BASF, which is on the DOW-30 Sustainability list, life cycle impacts and direct costs to the customer.

\section{Life Cycle Thinking in Product Development and Corporate Management}

Fuminiko KimURa of the University of Tokyo presented a computer-supported approach to life cycle design. Kimura requires, and integrates, a quality model into the LC design, which he presented in the context of an elevator case study. Supplemental models which predict product deterioration, upgrades and maintenance are also incorporated.

AkIRA SHImogaKI, of JMA Consultants, discussed the changes needed in the development process in order to innovate ecological products. Shimogaki examined environmental management with the aim of introducing measures which permit firms to restructure, and hence speed up, product development. Shimogaki noted that LCI databases have limitations in regards to materials. For example, some important materials are left out while there are others which may be inappropriately characterized. Shimogaki calls for sharing of components between products as well as information between firms.

ENRICO BENETTO, of the National Institute of Applied Sciences in Lyon, presented a model for product eco-innovation. This includes ecodesign, the development of environmentally responsible production plans, and green marketing. Benetto uses multicriteria methods to rank various design alternatives, though confides that eco-innovation is quite time consuming.

MARK GoEDKoOP of Pré Consultants presented a lecture entitled 'People, Planet and Profit Assessment of Product Service Systems'. Goedkoop is looking, with PriceWaterhouseCoopers and INSEAD, as to how the environment and social factors influence profitability. More specifically, based on a preliminary inventory, they attempt to identify potential costs, benefits and opportunities as a means to quantify sustainability. Pré uses five types of cost, including direct and indirect expenses borne by the firm, as well as potential liability in the supply chain. Intangible costs which can effect image or satisfaction as well as societal costs, not yet paid by firms, are also included. The latter is an extension of the polluter pays principle. As some of these costs are not certain to be borne, Goedkoop uses Monte Carlo simulations which include probabilities and potential damages. His project has a two year duration and intends to conclude with a guidebook.

MATTHIAS FINKBEINER of DaimlerChrysler gave an overview of life cycle design methods and examples in automotive product development. He noted that he felt LCA was a tool suited for Design for Environment ( $D F E$ ) with the caveat that the environmental management group, in any multinational, is dwarfed by the product development teams, and therefore must integrate into this culture, as any cross-functional unit must. In this sense, Finkbeiner sees Design for Environment, or ecodesign, within an organization, in a similar role to human resources. Finkbeiner then noted that the degree of ecodesign varied between products, with higher production volumes, and consumer demand for information, pushing firms to move beyond compliance. He also stated that he believes LCA will not survive as a stand-alone tool within firms. In the long term, the internal use of LCA to improve the product will be necessary. In terms of the automobile design process, Finkbeiner noted that as one moves from targets to various intermediate milestones, including prototypes, LCA can be used, on a complete car, to check if the new design is on specification. Using the LCA on the new E-class Mercedes, Finkbeiner showed that some emissions during the use phase, for example $\mathrm{NO}_{\mathrm{x}}$, are dominated by upstream processes (e.g. refining). Therefore, legislation has succeeded in 
rendering automobile use more environmentally efficient, and new standards are required to further improve the life cycle burdens. He, therefore, recommends separating fuel production and tailpipe emissions as two sub-categories of the use phase. Finkbeiner concluded that material choice is vehicle, and even part, dependent. Furthermore, the tradeoff between fuel savings through weight reduction and increased recyclability is also product specific.

TOMOHIKO SAKAO of the Mitsubishi Research Institute combined quality function deployment for the environment (QFDE) with LCA as part of a DfE toolbox. QFDE considers environmental consciousness as a quality, identifying the 'customers' as green consumers, recyclers and the environment itself. In this way, QFD is linked, intrinsically, to environmental improvement. In a case study on an printed wiring board (PWB), the LCA identified electricity, LPG and heavy oil as the most significant items, compared with the core $\mathrm{PWB}$, insulation resin and inner wiring, for the QFDE. These two lists coincide in regards to processes, with injection molding requiring modification in four of the above parameters. In terms of impacts, energy and materials were common to both methods. Overall, Sakao found the methods complimentary in regards to design stages, though quite different in their inventory needs.

ERWIN LINDEIJER of TNO Industrial Technology discussed the EcoScan tool for the evaluation of design choices based on LCA. EcoScan, with the capability to input data from various existing databases, is intended to be used by designers. It includes simplified design for end-of-life tools, and is intended to optimize disassembly and materials recycling. EcoScan provides, in place of a full impact assessment, a single environmental score, with averaged rather than spatially differentiated data. EcoScan is used by several multinationals, as well as in academia as a teaching tool. A land use case study was presented.

JESSICA LAGERSTEDT, of the Royal Institute of Technology in Stockholm, presented a case study on functional and environmental product attributes in new car designs, a cooperative project carried out with MIT. Lagerstedt noted the communication gaps between designers of a multi-attribute product and environmental managers. The latter present extended lists of environmental attributes which can be overwhelming, even for components or materials. Lagerstedt uses a functional profile to evaluate early design possibilities. This included, for the automobile, attributes, expressed in designer jargon, such as lifetime, reliability, safety, ergonomics, aesthetics and recyclablility. The study was carried out with an international group of stakeholders with the aim to launch a new vehicle intended for sustainable urban systems. At present the car has been designed, though not yet put into production. Balancing environmental cost and functional benefits (i.e. the functional environmental matrix) was used to identify areas in the design that required detailed modeling.

SHIGEYUKI MIYAMOTO of NEC discussed ecodesign for IT systems. The negative environmental affects of IT systems typically include energy consumption, generation of waste materials and harmful chemicals. The case study involved an environmental load assessment for an e-learning system, with $\mathrm{CO}_{2}$ selected as the environmental indicator. Both LCA and business improvement analyses (BIA) were carried out (BIA software is available from NEC for IT systems). The recycling of servers, PCs and CDROMs were included in the analyses, with the functional unit being 40 educational lessons per month. The control case (conventional learning) involved fifty participants who were involved in each 3-hour lesson with an average transport distance of 60 $\mathrm{km}$. Overall, e-learning resulted in an $87 \%$ reduction in $\mathrm{CO}_{2}$.

DAVID HUNKELER of AQUA+TECH in Geneva reviewed the drivers for and entry gates to life cycle management (LCM). The presentation, which will be summarized in an article in the International Journal of LCA, was based on the four years of deliberation of the SETAC-Europe Working Group (WG) on LCM. In brief, the SETAC WG, who studied ten cases and more than twenty tools, has defined LCM, as well as what LCM is not. It has also correlated the key drivers and motivators for LCM as a function of product type and corporate size, and examined which corporate functions are responsible for the integration of LCM. In all cases, the WG studied product related assessments combining environmental and economic information, over a life cycle. Hence, the WG addressed the private sector, so as to not conflict with other SETAC WGs, which examined public sector related issues and decision-making processes and tools.

MIDORI HATA of Fuji Xerox presented a paper on product management based on dynamic life cycle thinking. Challenges in the design of mass consumer products are complicated by the uncertainty, and distribution, in product recovery at the end of life. In addition, returned electronic products have experienced very different use profiles, providing a second dimension to the product recovery attributes. Therefore, Fuji Xerox uses probability distribution functions to model these characteristics, permitting the 'detention' curve to change with time. As a specific example, both the average number of copies made per month, and the duration of use time of the machine, differ by over an order of magnitude for photocopiers. In conclusion, if all products are recovered and reused, $\mathrm{CO}_{2}$ savings are 10,000 metric tons. If only components are reused, the savings would be reduced to 5,000 metric tons of $\mathrm{CO}_{2}$. The payback is rapid, since a $14 \% \mathrm{CO}_{2}$ savings is achieved by reuse of $1 \%$ of components, if the components are applied to the same product.

GERALD REBITZER of the Swiss Federal Institute of Technology discussed life cycle costing (LCC) in the process industries. Following an introduction into the utility of $L C C$, Rebitzer presented a case on water treatment, specifically examining the effect of chemicals (flocculants and coagulants) on the environmental burden and economic cost of waste water treatment and the concomitant sludge disposal. Three scenarios were examined where coagulants were used alone or together with flocculants. A fourth scenario studied chemical free treatment. In all cases medium sized water treatment plants were studied, with $10^{4-5}$ person equivalents of water treated using a variety of end-of-life sludge disposal scenarios, involving various transport distances. Specifically, Rebitzer sought to identify the cost drivers in the provision of a clean water service with the aim of identifying key areas where environmental improvements are possible. Overall, the scenarios which employed coagulants and flocculants had lower impacts by as much as a factor of two, for example in GWP. The major environmental burdens arose from sludge drying and transport to disposal, with the transport approximately $40 \%$ higher. Interestingly, these two attributes also dominated the life cycle costs, though in economic terms the drying was dominant. Variable costs were in the order of 70-90 Dollars per person per annum and can be reduced by improving the dry content of the sludge and reducing transport distance. For example, a reduction in transport distance from 100 to $40 \mathrm{~km}$ reduces costs by one-third. Rebitzer recommended that anything that you can do, chemically, to increase the dry material level, provides important environmental and economic benefits. He concluded that LCC can be carried out 
with very little marginal effort if an LCI has already been established, clearly recommending joint $\mathrm{LCC}^{2}$ and LCA.

JUNICHI KASAI of Isuzu Motors showed examples of LCC and LCA for the recycling of automotive plastic parts. The analyses were based on $\mathrm{GaBi} 3$ and EcoIndicator' 95 . Isuzu has studied the recycling of polypropylene (PP) bumpers into minor exterior parts of small trucks (e.g. tire house liner). At present, $10 \%$ of the tire house liners come from recycled PP. Overall, the LCIA did not result in a conclusive benefit of virgin or recycled plastics, with some categories better for both, though recycling was marginally better. The LC costs were approximately $5 \%$ lower for the recycled option, though the breakdown of costs was quite different. Recycling had large costs involved in palletizing $(46 \%)$ and transport $(35 \%)$ while the virgin PP's costs were dominated by landfilling (62\%) and dismantling (36\%). Incineration was not included as an option.

MARKus STURz of the Motorola Advanced Technology Center discussed a green cost management system for electrical and electronic equipment (EEE). The paper summarized a European project on greening the European EEE industry. This was motivated by the rising level of electronic scrap in the $\mathrm{EU}$, which grows at $3.5 \%$ per annum on its present 8 million ton level. The new EU directives, WEEE (Directive on Waste Electrical and Electronic Equipment) and RoHS (Directive on the Restriction of the Use of Certain Hazardous Substances in Electrical and Electronic Equipment), are expected to increase costs by $5-15 \%$. Therefore, the ten partners in the so-called grEEEn-project have the objective of homogenizing cost management, as well as developing a software and database. Their target groups are the environmental experts who are part of the product design teams of companies. The grEEEn tool, which uses both process and product models and is still under development, includes an estimation of the degree of legal compliance. The research includes five case studies ranging from medical equipment, PCs, a mobile phone and smart distribution nodes for automobiles to a halogen-free component. 'GrEEEn' will be based on scenarios and permit what-if analysis.

\section{Appendix:}

\section{Glossary of Some LCA Related Terms Used at the 5th-ICEB}

Business Improvement Analysis $(B / A)$ is a method for comparing environmental loads in the operation stage before and after a new product is introduced.

Design for Environment: A general concept for a toolbox of methods for incorporating environmental considerations into the design process.

Dynamic LCA (see Time-specific LCA) adds a kinetic dimension to a LCA. This is typically a second product attribute related to the frequency in usage or the lifetime of the product after purchase. Hence, the dynamics typically impact on the use and end-of-life stages.

Ecodesign: see Design for Environment

Ecoefficiency. There have been several definitions at the 5th-ICEB.Therefore, it is difficult to give an unambiguous explanation. However, one could say that ecoefficiency is concerned with creating more value with less impact (as formulated by the World Business Council for Sustainable Development, see DeSimone and Popoff 2000).

Eco-innovation includes ecodesign (Design for Environment), the development of environmentally responsible production processes and networks, and green marketing.

EcoRatings are used in the financial sector in categorizing firms as potential investment targets by mutual funds.

EcoScan is a software based on LCA, and intended for designers, with the capability to input data from various existing databases. It includes simplified design for end-of-life tools. EcoScan provides, in

2 SETAC-Europe has begun, at the Barcelona meeting on December 5th, 2002, a new working group on life cycle costing. Its agenda will include methodological guidance, data format and case studies. place of a full impact assessment, a single environmental score, with averaged rather than spatially differentiated data.

Environmental Load Analysis (ELA) is a partial LCA focusing on a given impact, such as $\mathrm{CO}_{2}$.

Factor $X$ is an approach to assessing sustainability and the reductions in material or energy intensity required to permit continued growth. The approach is general a concept, applied globally to targets set, for example, in Rio. However, specific calculations are used in green accounting for product evolution.

Green Procurement is a general concept for purchasing which includes environmental constraints.

Green Productivity Ratio divides a product output measure by an input parameter normalized per unit of environmental effect. in general, green productivity is a strategy for enhancing productivity and environmental performance in a socio-economic context.

Integrated Product Policy can be described as an integrated toolbox for the implementation of sustainable development on a product level. It includes the demand as well as the supply side of the value chain.

Life Cycle Costing ( $L C C$ ) does not have a generally accepted definition, and is itself the topic of a new SETAC-Europe working group, which has began its mandate at the end of 2002. Generically, one could say that LCC likely involves the economic assessment of all monetary flows associated with the product over its life cycle.

Life Cycle Design is an engineering approach to take the complete life cycle of products into account. This may involve Design for Environment, but also other concepts such as Life Cycle Costing.

A Lorenz Curve depicts the disparity in income distribution, with a larger bend in the curve indicating a significant fraction of the population below the poverty line or above the income where employment is not required.

Pollution Prevention is an approach advocated in the early 1970 s after end-of-pipe solutions came out of fashion and seeks to eliminate waste and emission streams, at their source, as a means for concomitant environmental improvement and economic savings.

Pollution Prevention Pays (PPP) is an approach initially developed by $3 \mathrm{M}$, and summarized in a 1970 s book by Michael Royston (1979), which documents the savings that preventative actions can yield in manufacturing based firms.

Quality Function Deployment (QFD) is a widespread design approach used in the early planning phases and combines engineering metrics and technical benchmarking with customer perception. The output of the two-stage QFD process is a prioritization for design.

Quality Function Deployment for Environment (QFDE) considers environmental consciousness as a quality, identifying the 'customers' as green consumers, recyclers and the environment itself.

Reduce-Reuse-Recycle Hierarchy is used by the European Commission to set policy and certification standards and implies that prevention and prolongation of the product life cycle are preferred, unless otherwise proven, for example by LCA, to material or energy recycling (see Integrated Product Policy).

Scenario-based LCA takes a static system approach in a virtual system, or LC, model. All options, or product alternatives, are modeled concurrently rather than in series. One then toggles between options by adjusting the weighting of the flow parameters between each alternative. Scenario parameters are modified by incorporating external studies, predictions or expectations in the product life cycles.

Time-specific LCA (see Dynamic LCA) approaches trace the actual data occurring along the manufacturing process within a firm.

Trophic Level Analysis uses analogies from biological food chains to depict industrialization. As an example, Kalundborg, near Copenhagen, with its extensive interactions between manufacturers, therefore has a much more compact tropic web than, for example, the copperfiow in Boston, or Japan.

Trophic Net/Web is a diagram with analogies to the biological system that depicts the interactions between organisms, or in an industrial ecology approach, products and byproducts.

\section{References}

Inaba A, Hunkeler D, Rebitzer G, Finkbeiner M, Siegenthaler C, Saur K (2003): The Fifth International Conference on Ecobalances - Practical Tools and Thoughtful Principles for Sustainability. Int J LCA 8 (1) 1-5

Hunkeler D, Biswas G (2000): Return on Environment - An Objective Indicator to Validate Life Cycle Assessments? Int J LCA 5 (6) 358-362

DeSimone D, Popoff F (1997): Eco-Efficiency - The Business Link to Sustainable Development. MIT Press, Cambridge, USA

Royston MG (1979): Pollution Prevention Pays, Pergamon Press, Oxford, UK

Saling P, Kicherer A, Dittrich-Krämer B, Wittlinger R, Zombik W, Schmidt I, Schrott W (2002): Eco-efficiency Analysis by BASF: The Method. Int J LCA 7 (4) 203-218 